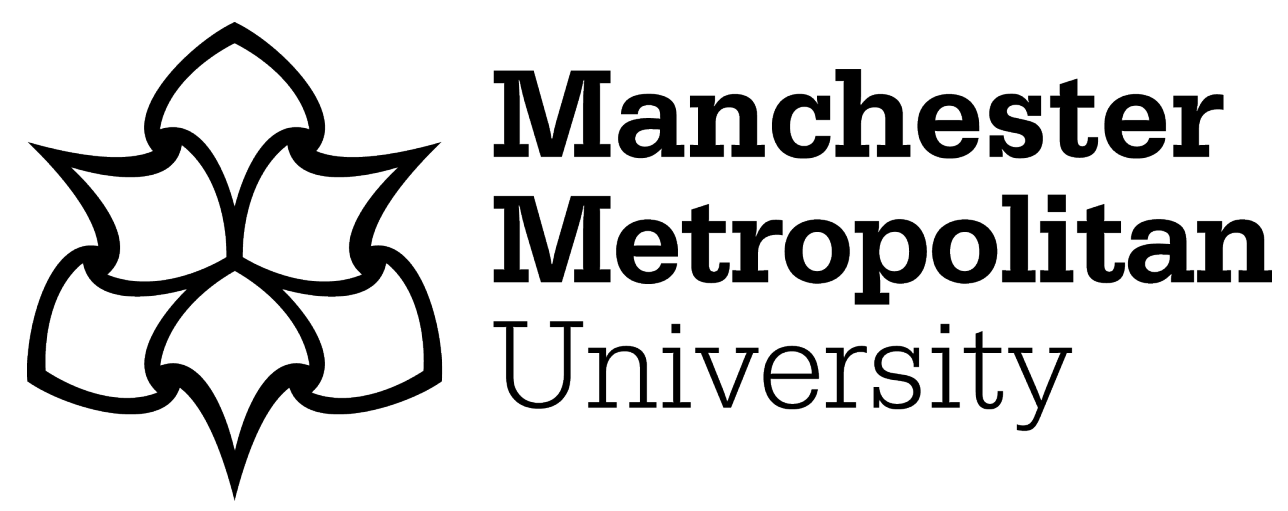

Rimmer-Piekarczyk, Rachel (2018) Self-somatic authority: Exploring the cultivation of somatic intelligence through a dialogic approach to self-reflection in dance technique learning. Journal of Dance \& Somatic Practices, 10 (1). pp. 95-110. ISSN 1757-1871

Downloaded from: https://e-space.mmu.ac.uk/621170/

Publisher: Intellect

DOI: https://doi.org/10.1386/jdsp.10.1.95_1

Please cite the published version 


\section{Self-somatic authority:}

exploring the cultivation

of somatic intelligence

through a dialogic approach

to self-reflection in dance

technique learning

\section{abStract}

\section{keywordS}

1. This article contemplates the notion of a 'self-somatic authority' by exploring the

2. relationship between dialogue, self-reflection and the cultivation of somatic intel-

3. ligence. Drawing on Mikhail Bakhtin's notion of dialogism, and specifically his

4. concepts of 'authoritative discourse' and 'internally persuasive discourse', the author explores whether a dialogic approach to teaching release-based contemporary dance technique in higher education can enable learners to meaningfully reflect on their self

somatic authority dialogue dance technique reflection action research practice, subsequently leading to a stronger sense of somatic intelligence. To exam8. ine the efficacy of this pedagogical approach, responses from a focus group discus9. sion conducted with a group of first year students who participated in a cycle of 10. action research are examined; the teacher's reflective journal notes are also analysed. 11. Drawing on the data, the author proposes that a dialogic approach to nurturing 
self-reflection in the dance technique class constructs a particular kind of somaticinformed pedagogy that not only appears to facilitate 'self-somatic authority', but also presents unexpected challenges and contradictions.

\section{introduction}

This article explores whether a dialogic approach to self-reflection in the higher education dance technique class can cultivate a stronger sense of somatic intelligence amongst students in the first year of their undergraduate dance degree. This piece of action research does not aim to investigate the application of a specific somatic practice into the dance technique class. Rather, the research is concerned with exploring the relationship between dialogue, self-reflection and somatic intelligence. By analysing data collected during a cycle of action research, I contemplate the possibility that through dialogue and somatic sensing, meaningful self-reflection can be facilitated, which can subsequently lead to the development of somatic intelligence. Building on existing dance research, I consider the notion of somatic authority from a different perspective, proposing that the pedagogical approach used in this study nurtures a particular kind of somatic authority, one that I refer to as 'self-somatic authority'. In my analysis of the data, I suggest that 'self-somatic authority' foregrounds the notion of self by considering how one's sense of self is constructed and authored through the many dialogues that occur in the dance technique learning environment.

This enquiry is grounded in critical and somatic learning perspectives and has emerged from a research project in which the overarching aim is to investigate methods for deconstructing the perceived hierarchical relation between teacher and students by opening up a dialogical relationship between us and examining this from a reflexive position. I have investigated these ideas during two consecutive cycles of action research. This article presents the findings from the second cycle of research during which I investigated pedagogical methods for challenging a question-answer dichotomy that I perceived to be present in my teaching. In this article, I attempt to create a dialogical analysis, which not only discusses the positive effects of a dialogic approach to teaching and learning in dance technique, but also the problematic and potentially dangerous aspects.

I use Mikhail Bakhtin's concepts of 'authoritative discourse' (AD) and 'internally persuasive discourse' (IPD) (1981: 345) as lenses to analyse my own reflective journal notes and the focus group discussion responses of seven first year dance technique students who were invited to discuss their perceptions of the pedagogical methods used. I have found Bakhtin's theory of dialogism and the research of scholars who have responded to Bakhtin's work (Matusov and von Duyke 2010) particularly useful for creating a contextual framework around my research, enabling me to contribute to the current discourse around dialogic pedagogy in dance education and beyond (Anttila 2007b; Dyer 2014; Dryburgh and Jackson 2016; Alexander 2017, 2008; McArthur and Huxham 2013; Skidmore and Murakami 2016).

\section{Somatic authority}

Somatic theorist Johnson (1992) suggests that western cultures have traditionally promoted a mind/body split that privileges the mind over the body and disconnects the individual from the felt, embodied experience. This 
1. mind/body split is perpetuated through the cultural obsession with objec2. tifying the external appearance of the body. Referencing somatic pioneer 3. F. Matthias Alexander, Johnson (1992: 160) suggests that fundamental 4. misuse of the body is rooted in a cultural tendency to 'locate authority 5. outside ourselves' through a 'desire to please outside authorities'. Dance 6. educator Jill Green has written extensively on the subject of somatic author7. ity $(1998,1999,2001,2002)$ in relation to dance education, with specific 8. attention towards exploring ideas related to the ideal body. Drawing on 9. Hanna's (1988) definition of the term 'somatic', Green (1998: 7) defines 10. the notion of somatic authority as the ability to be aware of 'what goes 11. on inside the body rather than a sole focus on what the body looks like 12. or how it "should" behave'. She suggests that dance educators who teach 13. from a somatic perspective 'tend to include students in the process of 14. learning dance by bringing awareness to inner sensory and proprioceptive 15. processes' (1998: 7). Such processes tend to emphasize the notion of closely 16. observing oneself through a process of sensing, for example, sensing the 17. body's weight by exploring the relationship with gravity, slowing move18. ments down to observe bodily sensations and taking time to sense the 19. breath (Batson 2009; Eddy 2009). One may also accept interventions from 20. the educator or other learners through touch-based activities or verbal 21. input (Eddy 2009).

22.

23.

It is clear that somatic-based pedagogies aim to work from the inside out, as opposed to objectifying the body by solely acknowledging the external appearance of the movement. In relation to dance technique education, Bannon (2010: 50) suggests that 'increasing the engagement with experiential "somatica"' could be a way for educators to develop new ways of learning in dance technique that enable learners to 'achieve knowledge that is particular' (2010: 50). Many studies have investigated how dance technique students might develop such 'particular' knowledge through the use of constructivist, feminist and somatic-based pedagogies (Hanstein 1990; Stinson 1993; Shapiro 1998; Green 1998, 1999; Brodie and Lobel 2004; Stevens 2006; Enghauser 2007; Råman 2009; Dyer 2009, 2010; Fortin et al. 2009; Weber 2009; Stanton 2011; Aceto 2012). Findings from these studies appear to validate the use of somatic-based pedagogies as an approach for enabling students to develop a greater sense of autonomy in the dance technique class. As opposed to traditional pedagogical paradigms that tend to establish a hierarchical relationship whereby students essentially 'give their bodies to their teachers' (Green 1999: 81), it is thought that the use of somatic-based pedagogies facilitates a shift of responsibility that enables learners to take more ownership of their bodies.

In addition, findings from studies by Fortin (1998) and Fortin et al. (2002) demonstrate that somatic-based pedagogies not only empower students but also teachers, as many are freed from the expectation to be the sole providers of knowledge. However, other research reveals that some learners may be unable to see the value of such pedagogies and highlight the challenges that both students and teachers face (Green 1999; Fortin et al. 2009; Dyer 2010). Going against the dominant discourse requires agency on the student's part (Fortin et al. 2009) and as some individuals may not yet be ready for this transition, somatic-based pedagogies may leave some individuals feeling out of their depth, confused or frustrated. This could lead to a pedagogical dilemma whereby tension occurs between teacher and student as both grapple with their expectations of the other. 
1. Bakhtin refers to that which is beyond the self as 'otherness' (Holquist 2002: 18)
2. Reflection and dialogue 1.

2.1 Reflection, self and the body 2 .

Reflection has been key in helping me to understand more about the expectations that my students and I have of each other, as well as making sense of the experiences that we engage in together in the dance technique class. Reflective practice underpins all models of action research (Bradbury 2015; McAteer 2013; McNiff 2013) and is generally defined as one's capacity to make sense of experience in relation to self, others and contextual environment (Ryan 2012). Reflection can function on a variety on levels ranging from basic to critical to reflexive or transformative reflection. Speaking about selfreflection in relation to artistic practice, Ryan (2012: 211) states:

The creative process opens up new ways of thinking about self and enhances inner sensory perception so that one is more attuned to the details of life and experience and more acutely aware 'self' in relation to others and to the world.

In the dance learning environment, the body is the primary locus for processing experience and sensory perception is particularly heightened. As such, it seems that the sensing of one's own body, as well as other bodies, is an essential component in facilitating self-reflection in dance, a process that contributes towards one's understanding of self. As dance researcher Anttila (2007a: 84) suggests, reflection in a dance learning setting is generally 'situated in and mediated through the body' and it is through the act of moving one's body that cognitive, or mental reflections emerge. Exploring the connected state between one's 'neural and cognitive systems' (2007a: 83), Anttila draws on the work of key scholars in the field of consciousness to propose that although the brain has been historically perceived as responsible for cognitive thinking processes that control the body, there is now a greater understanding of the way our bodies shape our thinking processes. According to Anttila (2007a: 97) 'The body and the brain mutually determine each other's behaviour' and in fact, reflection in a dance learning environment generally transpires from the act of moving.

During the technique classes in this study, students were invited to reflect on their experiences of moving in a variety of ways, always beginning from and returning to their bodies. It was hoped that through continuous and varied self-reflection, students could begin a process of understanding more about themselves as learners of dance, for example, their own movement tendencies and their preferred learning style/s as well as making sense of their position as learners in relation to each other and the teacher. Data analysis of the focus group discussion responses later revealed that self-reflection would be an essential factor in facilitating somatic intelligence as it became evident that some of the skills required for careful body listening were being nurtured through the act of reflecting. Furthermore, data analysis also revealed that the most quality self-reflection occurred when students were interacting with each other and the broader environment, a phenomenon that I have come to understand as 'dialogue'.

\subsection{Dialogue and the IPD}

Dialogue refers to the interactions between self and other, or self and the world ${ }^{1}$ and is thus a condition of human existence. It is the triangulation between self, world and the relation between these two entities that
2. 
for Bakhtin, constitutes the phenomenon of dialogue: 'In dialogism, the very capacity to have consciousness is based on otherness [...] It cannot be stressed enough that for him [Bakhtin] "self" is dialogic, a relation [...] a relation of simultaneity' (Holquist 2002: 18-19). More specifically, Bakhtin refers to the notion of a 'center' to further discuss the relation between self and other, suggesting that each human perceives the world from their own 'center'. Thus, dialogism is built on the premise of acknowledging the 'differential relation between a center and all that is not that center' (Holquist 2002: 18).

Bakhtin's notion of dialogism can be considered in relation to the values of critical pedagogy, an educational philosophy grounded in the work of Freire (1996). Freire proposes that in order to enable learners to develop a deeper understanding of the world, they must be encouraged to question the sociocultural reality within which they exist through the act of critical thinking. According to Freire, this relies on the learner's ability to critically engage with ideas and perspectives beyond the realm of their own experience, involving what he calls'true dialogue' (1996: 73) and it is only through true dialogue and critical thinking that change can occur. Such change could concern the repositioning of teacher and student, meaning that the teacher-student relationship can progress beyond the didactic transmission of knowledge, or 'banking' to borrow Freire's (1996:53) term, in favour of enabling a more collaborative learning environment. It could be said that true dialogue enables this shift to occur; McArthur and Huxham (2013: 96) state that in order for teacher and students to be in dialogue with each other, teachers must 'find ways to let students know that they too are open to learn through the relationship' and this willingness to learn must be genuine, not superficial. Indeed, as Freire (1996: 71) writes, 'How can I dialogue if I always project my ignorance onto others and never perceive my own?'

Furthermore, this repositioning can extend to the relationship between students. According to Ladyshewsky (2013), dialogue between peers should create opportunities for students to meaningfully reflect on similarities and discrepancies and to make useful discoveries through this process. Celebrating difference is also a key idea within Bakhtin's concept of dialogism; only through recognizing 'the multiplicity of perspectives and voices' (Robinson 2011: unpaginated) can the self begin to reflect on and alter aspects of her own consciousness. Within this basic condition of existence, humans are 'transformed through dialogue, fusing with parts of the other's discourse. The other's response can change everything in one's own consciousness or perspective' (2011: unpaginated).

The notion of changing one's own consciousness or perspective as a consequence of 'fusing with parts of the other's discourse' is a key idea within Bakhtin's concept of IPD, which originates from his analysis of dialogism in literary texts. Bakhtin defines IPD in the following way:

Internally persuasive discourse - as opposed to one that is externally authoritative - is, as it is affirmed through assimilation, tightly interwoven with 'one's own word'. In the everyday round of our consciousness, the internally persuasive word is half-ours and half-someone else's. Its creativity and productiveness consist precisely in the fact that such a word awakens new and independent words, that it organizes masses of our words from within, and does not remain in an isolated and static condition.

(1981: 345)
2. Freire's (1996) concept of 'banking' refers to learners being regarded as empty containers into which teachers literally pour knowledge. 
3. The findings from the first action research cycle can be found in Rimmer (2017).

4. Although each action research cycle was conducted with different students, to maintain consistency in the study, both cycles took place in the same first year module at the same time of year for a similar number of sessions.
Matusov and von Duyke (2010) have applied Bakhtin's concept of IPD within an educational context. They suggest that 'IPD and its opposition to the authoritative discourse (AD) helps educators move away from the conventional notion of learning as a transmission of knowledge from the teacher (and/or the official text) to the student' (2010: 176). It is the presence of AD that supports the transference of one dominant, fixed meaning from teacher to student. In contrast, IPD is dialogical in the sense that 'One's own discourse is gradually and slowly wrought of others' words that have been acknowledged and assimilated' (Bakhtin 1981: 345) and one's own discourse is considered to be fluid and changeable.

\subsection{Bodily dialogues}

The presence of dialogue in the dance technique class involves opportunities for students to perceive their own movement and the movement of others from multiple perspectives. Anttila (2007b) explains that in dance learning, being in dialogue with one's own body and the bodies of others involves bodily acts such as sensing, feeling, listening and touching. Drawing on the research of Buber (1937), Dryburgh and Jackson (2016) propose that dialogue in dance learning occurs by literally turning towards the other and experiencing from the other side. The term 'word' frequently appears in Bakhtin's writing on dialogue and although it may traditionally be associated with verbal or text-based utterances, when considered from a phenomenological perspective, the notion of 'word' adopts a broader, more holistic meaning. Indeed, Bakhtin's recognition of the persuasive discourse as something that is internalized appears to be strongly located in phenomenological thought and resonates with the notion of bodily dialogues.

Changing one's perspective on the world involves much more than abstract thinking; it is a process that integrates mind and body collectively. Hence, for me, IPD in a dance learning environment refers to the embodied assimilation of multiple perspectives and ideas, and the shaping of one's own bodily discourse that emerges from engagement with these ideas. Since learning and knowledge generation in dance concerns 'the inclusion of theoretical, practical, and existential dimensions, which cannot be distinguished from each other, but instead are interrelated and dependent on each other' (Andersson and Thorgersen 2015: 3), in this article, I use Bakhtin's notion of 'word' in a way that is inclusive of all the verbal and bodily exchanges that occur between teacher and students.

\section{3. action ReSeaRch cycle two: context} 3.1 Research methodology

This action research cycle built on the research findings from Cycle One, which was conducted during the spring term of 2015. ${ }^{3}$ The second cycle took place during the spring term of 2016, beginning on the 12 January and ending on 15 March. ${ }^{4}$ As a methodology, educational action research is based on the premise of practitioner enquiry and studies generally take place within normal teaching practice (McAteer 2013). My study took place over a series of eight release-based technique classes that I delivered as part of a Year One module called Dance Practices One (DP1). DP1 consists of three assessed elements, which are a choreographic assignment, classes in dance technique and a reflective essay. Although practice in dance technique is assessed, it is
1. 2. 
designed to support the broader choreographic and performance work within the module and is therefore continuously assessed throughout the duration of the term.

Prior to the cycle commencing, I discussed the study with all of the students enrolled onto the module and gave them an information sheet and consent form to sign. Students were not obliged to take part in the study, but were informed that if they chose not to, they were still expected to attend all technique classes as normal. Although action research is predominantly teacherled, the involvement of students means that studies can take on a collaborative aspect (McAteer 2013). To help the students feel invested in the study, I found it was important to state that the research would not be possible without their insights and therefore, I perceived them as collaborators. Furthermore, I felt it was important to be explicit with the students regarding my reasons for conducting this study. I spoke openly with them about my own experiences as a learner of dance and explained how this had informed and shaped my interests as a teacher. I explained that a key aspect of the research was to try and implement teaching methods that would help students to become more independent, reflective learners of dance technique and this may require them to work in ways that were new or different to previous learning experiences. I found that my willingness to be open with the students in this way encouraged them to be more forthcoming with regards to sharing their own experiences as learners of dance during class discussions. However, I am also highly aware of the power dynamics at play within this research and the ethical complexities of inviting students to voluntarily participate in a research study that is embedded within a compulsory module on their degree course. Although these ideas are taken into consideration in the data analysis, a full interrogation of power dynamics is beyond the scope of this article.

On Wednesday, 9 March, the penultimate week of the action research, seven students voluntarily took part in a focus group discussion. During the action research, I recorded my immediate thoughts after each session by writing in my own reflective journal. All technique classes and the focus group were filmed for the purposes of data collection. A thematic analysis approach has been employed to analyse the data from each source and pseudonyms are used in this article to protect the anonymity of the participants.

\subsection{Research aims}

During the second cycle, the primary aim was to explore how opportunities for dialogue could be created and to understand how this dialogue could enable students to engage in meaningful reflection around their dance technique practice. I also wanted to explore whether a dialogic approach to learning in dance technique could deconstruct the perceived hierarchical relationship between teacher and students that many first years expect when initially arriving at university (Stevens 2006). These research aims led me to develop an interest in understanding how students' questions about the technique movement material could become initiators for dialogue. ${ }^{5}$ I was curious about the question-answer dichotomy that seemed to be at play when a student posed a question about one of the movement phrases to me. Until this point in my teaching career, I had instinctively offered one direct answer to students' questions, assuming that in my role as 'teacher', this was what was expected of me. It was not until I reflected on this idea more deeply that I began to consider the kind of dynamic that was being established between
5. I have previously discussed my interest in questions in Rimmer (2016). 
us. With further reference to Bannon's (2010) research, the idea of offering only one 'answer' seemed to directly contradict the notion of enabling learners to 'achieve knowledge that is particular' by conveying an underlying message that there is only one way to approach something. As such, so many other possibilities appeared to be negated. This idea is made more complex by the prevailing perception that learning in the dance technique class is comprised of rights and wrongs (Dyer 2009), an ideology that immediately discourages a culture of enquiry and hinders both teachers' and students' ability to work in an explorative way.

With this in mind, Cycle Two became concerned with attempting to collapse this question-answer dichotomy by dealing with students' questions in a different way. For example, if a student asked a question about the placement of weight at a specific moment in a phrase, I resisted offering an answer myself in favour of using the question as an invitation for everyone to explore possible 'answers', including myself. By passing the question back to the group, the concept of weight placement would be then explored in more depth and such exploration would be both physical and discursive.

\subsection{Individual and collaborative dialogues}

In light of Anttila's (2007b) research, students investigated the idea of weight placement by engaging in bodily dialogues both individually and in collaboration with others. Individually, they were encouraged to explore by moving independently, establishing a dialogue with their own body through careful listening that was guided by me. Dryburgh and Jackson (2016: 5) describe such a dialogue with one's own body as an 'inner dialogue [...] a somatic awareness that promotes authenticity and agency [...] thoughtful action that provides the dancer with feedback from the knowing body'. Students were also invited to explore in dialogue with others during peer observation and feedback tasks, improvisations and touch-based activities, again facilitated by me. These dialogues presented opportunities for individuals to share what had been discovered during the independent explorations and to investigate further by collaborating with others.

Students were then invited to share their findings within a broader class discussion. During these broader group dialogues, students discussed what they had discovered and a range of ideas and approaches to the movement were considered. Consequently, multiple possible 'answers' to the original question were considered. During these discussions, I prompted students to reflect on their movement explorations by speaking about the felt experience in the first person. For example, I might ask 'can you describe the sensation of placing all of your weight on your right leg?' or 'how did it feel different to shift your weight in that way?'. This enabled a discourse around the somatic experience to develop. In light of these discussions, both the students and I would return to the original movement phrase and I would encourage them to experiment further with weight placement. The notion of continuous exploration and reflection was strongly emphasized throughout this cycle of research.

\subsection{Peer feedback activities}

Alongside this activity, students were frequently invited to engage in peer feedback activities that involved partnering tasks during which they would observe each other dancing and offer feedback on specific aspects of their partner's practice. As opposed to merely pointing out the 'positive' or 'negative' aspects 
50.

51.

52. of their partner's dancing, I attempted to encourage students to structure feedback in a critical way, responding to Ladyshewsky's (2013) model of engaged feedback. ${ }^{6}$ Although a critique of the challenges of peer feedback is beyond the scope of this article, data analysis demonstrates that peer feedback activities facilitated further opportunities for dialogue, as discussed in Section 4.2.

\section{4. findings}

\subsection{Body listening: Self-somatic authority}

The original aim for this research was to investigate how reflection could be facilitated through a dialogic approach to learning. However, analysis of the data collected reveals an additional finding concerning the notion of somatic authority. Data analysis suggests that the pedagogical approach used in this research appeared to construct a somatic-informed pedagogy that was built around the notion of reflecting on the first-person experience of self. Building on the work of Green (1998, 1999, 2001, 2002), I would like to propose that this pedagogical approach develops a particular kind of somatic authority, one that foregrounds the notion of 'self' and considers how self is constructed through the dialogues that occur the dance technique learning environment. This idea is grounded in the belief that for dancers, self-reflection and somatic intelligence are inextricably connected and that reflection is an essential part of authoring one's own sense of self.

In light of this idea, data analysis indicates that through dialogue, students were able to reflect on their understanding of technical movement concepts both individually and in collaboration with others. For some students, this reflection appeared to initiate a process of body listening that appears to support the development of their own self-somatic authority. For example, Gillian said:

I think for me it's been more of an exploration of what my body can do, or is doing. I'm certainly looking at what I should be doing, for example, when we're doing the parallel or reverse stuff, but for me it's learning what my body wants to do.

Gillian's response indicates that a dialogic approach to learning has enabled her to listen more closely to her body. Resonating with Green's (1998) research, as well as focusing on what she believes she'should' be doing, Gillian appears to be paying equal attention towards what is happening inside her body and sensing what her body 'wants to do'. Gillian's comments were echoed by Michelle who said:

I feel this technique explores your body and your little habits and things. Like, for example, you know when we say about the arms and if you're pushing, in a normal technique class like your arm's here and then it goes here, but in yours, it's kind of do what you want, do what your body tells you to do - if that makes sense. Cos I think technique is when I've done it before - it's really strict, like you have to be here at this count, but with yours, it is free and it is exploring what you want to do and where you want to do it.

Here, Michelle is able to acknowledge that less emphasis was placed on achieving specific shapes with the body in favour of supporting a more intuitive
6. Drawing on my experience with Authentic Movement going forward, I would like to experiment with developing a 'witnessing' model of peer feedback for the technique class; this idea will inform future cycles of action research. 
approach to dance technique, one where she is able to explore her body and her 'habits'. In recognizing that she has been offered the autonomy to explore and reflect on her learning, Michelle's own sense of self-somatic authority may be developing. Furthermore, there is also a sense that Michelle understands she is being encouraged to go against the dominant discourse; she describes her prior experiences of dance technique as 'strict' but uses the word 'free' to illustrate her experience in these classes, denoting a sense of liberation. However, this also raises a question around the notion of being 'free' and whether this is ever truly possible within the social and cultural constraints of the institution such as the hierarchical ordering of staff and students and the broader ideologies of the university. Of course this is a tension that can be acknowledged, but not removed.

An excerpt from my own reflective journal reflects the themes in Gillian and Michelle's responses:

Some students appear to be confident enough to approach things more playfully now, testing movement ideas and exploring alternative ways into and out of the phrase material. Some students don't even need my permission to do this. It feels refreshing.

(Reflective journal entry from 23 February 2016)

By opening questions out to the group, dialogue gradually became a more common aspect of technique classes. As opposed to providing only one 'answer', a dialogic approach to 'answering' questions allowed multiple possible 'answers' or approaches to be contemplated. This idea can be considered in relation to Bakhtin's (1981) notions of AD and IPD. By imposing one dominant 'answer' or way of thinking about a movement concept, it could be argued that the teacher enforces an AD that limits the students' ability to think autonomously or creatively. When an $\mathrm{AD}$ is present, other possible discourses appear to be negated, in this case, alternative ways of considering or approaching technical movement ideas. Furthermore, imposing one dominant discourse feels like a'one size fits all' approach that hinders somatic sensing. When given the opportunity to listen to the information being offered by their bodies, learners can begin a process of movement exploration that starts from the position of their own bodies and leads to the development of somatic intelligence.

\subsection{Self-somatic authority and collaboration}

Focus group discussion findings also indicate that the cultivation of selfsomatic authority is, to some extent, a collaborative pursuit. When asked about their experiences of engaging in peer feedback activities, Gillian said:

People give you feedback that you hadn't even considered and everybody looks at things differently [...] every person when we've gone into a pair has given me completely different feedback and so it's nothing that I would have intelligently thought of.

Gillian's comment indicates that since each student experiences the technique class from their own 'center', learners are given the opportunity to reflect on their own movement through the eyes of their peers and potential areas for development may be identified. As Dawn said, 'I think we can

1. 2. 3. 4. 5. 6. 7. 8. 9. 10. 11. 
1. understand some mistakes or habits we have, but we can't really watch 2. ourselves dancing really, so it's really important that somebody else can watch 3. us and tell us 'that's wrong, that's ugly' or something'. Similarly, Fay said,'I feel 4. like when you're doing the dance you don't realise sometimes what your body 5. is doing because you can't see it'. These comments indicate that dialogue not only enables individuals to become aware of 'mistakes', but that it also highlights attributes that are unique to their way of moving. Thus, it could be said that the development of self-somatic authority is also supported by working with peers to highlight idiosyncrasies; if the self understands what makes her distinct from the other, then she can begin to explore and take ownership of these idiosyncrasies, reinforcing the notion of a self-somatic authority.

It seems, then, that the individual pursuit of developing self-somatic authority is strongly grounded in shared learning processes. As Bakhtin (1981: 345) writes; 'the internally persuasive word is half-ours and half-someone else's' [...] affirmed through assimilation, tightly interwoven with "one's own word"'. Hence, it would appear that one's own embodied knowledge develops through the process of assimilating with the other's 'word'. In the dance class, this process of assimilation happens during the collaborative practices of moving together, watching each other move and talking about moving; in other words, one's own way of moving is shaped and influenced by the movement of others. When asked whether observing their peers dancing helped students to reflect on their own dance practice, Michelle commented:

I think it's really useful because I think with dance, you do learn from watching. So for example, if I watch Gillian and Gillian does a move and I like it, I automatically copy her because I want to do it exactly how Gillian did it. But if I didn't watch Gillian I would never know, I would never learn, and I think in dance you learn your moves from other people doing them.

Michelle's response suggests that peer observation is a useful tool where selfdevelopment is concerned. Her comment also exemplifies the presence of an IPD; here, Michelle's own movement is literally persuaded by observing her classmates moving. However, her response also seems to contradict somatic thinking; if students learn their moves by 'copying', then this may indicate that some learners are more concerned with imitating the movement of others. This desire to imitate may have a detrimental, even dangerous effect on one's own somatic sensing. Here, one of the ongoing tensions of dance-technique learning is illuminated and since there is no straightforward answer to this dilemma, teacher and students must negotiate their way through it by openly reflecting on these ideas together.

\subsection{Further dangers of dialogue}

While collaboration and peer feedback may be useful, there is also an argument to suggest that one's potential for further development might be hindered. To examine the limiting or even dangerous aspects of the self-other relation, I find it useful to draw on the work of one of Bakhtin's contemporaries, JeanPaul Sartre (1957) who offers a different perspective on dialogue. In Sartre's concept of the body as 'theft', the self can never perceive her own body in the same way as the other, indeed she is 'utilized and known by the Other' (1957: 351) as an'object';' 'with the appearance of the Other's look I experience 
7. I find this an interesting idea to consider, not only in relation to peer feedback, but also in relation to the feedback processes that occur in the teacher-student relationship. the revelation of my being-as object'. Furthermore, Sartre suggests that to an extent, the self is defined by the other, a dangerous process that may result in 'the death of my possibilities' (1957: 271). Thus, it could be said that peer feedback activities may limit movement development if the self is restricted by the other's perception of her. With further reference to Sartre, Jefferson writes, 'The Other's image of the subject's ego has an authority which deprives the subject of any authoring capacity of his own' (1989: 160). Consequently, it may be difficult for one to develop her own sense of self-somatic authority while being defined by the gaze of the other.?

\subsection{Autonomy}

Some participants recognized that they had become more autonomous by using dialogue to search for 'answers' themselves. It was acknowledged that dialogue not only allowed students to understand more about themselves as dancers, but that it also helped them to prepare for future independent work. For example, Dawn said, 'You let us figure the answer out and that makes us think and to explore [...] we find the answer and that's really good for us and for our later career when we're going to work independently'. Gillian responded to Dawn's comment by saying,'I think the more questions we have, the more answers we get and the more we learn about ourselves and the more we kind of focus in on what we're doing and why we're doing it'. However, a response from Tara demonstrates that regardless of the dialogic approach, to some extent, she still perceived the dance technique class as a place where the teacher is primarily responsible for providing the correct answers:'See, I think I would want it more specific, like 'Tara you're doing it wrong', so I'd know, rather than it being broad'.

Tara's comment highlights another area of tension; irrespective of being encouraged to explore multiple possible 'answers' or ways of approaching movements, on many occasions during the discussion, participants used terms such as 'wrong' or 'mistake'. This may indicate that regardless of my attempts to enable students to go against the $\mathrm{AD}$, some participants still perceived there to be right and wrong ways to execute movements. Furthermore, the perception appears to be that ultimately, it is the teacher's responsibility to reveal and approve these rights and wrongs. With reference to Johnson's (1992) research, here it seems that Tara is locating authority beyond herself and instead placing it on the teacher. This demonstrates that for some students, the expectation of an $\mathrm{AD}$ may still have been present. However, it should be acknowledged that at the time of this study, these students were in their first year of their degree and at the beginning of their careers as dance artists. Consequently, it should be expected that student dance artists with this level of experience will inevitably seek help and approval from the teacher, not only because this may reflect their previous learning experiences in dance, but because they may not yet be experienced enough to trust their own judgement; this is a skill that develops over time. In recognition of this, I would like to take this opportunity to congratulate the students on their willingness to challenge themselves and to thank them for continuously surprising me.

\section{concluding thoughts}

Opening the door to dialogue with, and amongst my students has facilitated a culture shift in our technique classes. Data analysis indicates that for some students, a more enquiring, explorative approach towards learning has allowed
1.

2.

3.

4.

5.

6.

7.

8.

9.

10.

11.

12.

13.

14.

15.

16.

17.

18.

19.

20.

21.

22.

23.

24.

25.

26.

27.

28.

29.

30.

31.

32.

33.

34.

35.

36.

37.

38.

39.

40.

41.

42.

43.

44.

45.

46.

47.

48.

49.

50.

51.

52. 
1. varying degrees of reflection to occur. Students have not only reflected on

2. their understanding of technical movement concepts, but also on their role as

3. learners of dance technique; in some cases, learners have contemplated their

4. own sense of agency. The challenge of not being provided with straightfor-

5. ward answers from the teacher has meant that learners are required to listen

6. to their bodies more intuitively. This in turn has initiated a process of search-

7. ing for possible 'answers', using one's own body as a resource to do so. For

8. some students, this process of searching appears to have enabled a stronger

9. connection to the felt experience, possibly contributing towards the develop-

10. ment of self-somatic authority.

11. Since dialogue itself is relational in nature, this article cannot be concluded

12. without reflecting on the effects of this approach on my own teaching prac-

13. tice. Dialogue has, to some extent, unshackled me from the expectation to

14. provide 'answers'. Contemplating possible 'answers' in collaboration with my

15. students has been both challenging and empowering and has had a signifi-

16. cant impact on my teaching practice. For example, a question from a student

17. would often bring attention to something in the movement material that I

18. had not previously considered. Questions began to challenge me by requiring

19. me to reconsider and clarify details within the movement material. Returning

20. to the movement in this way presented valuable opportunities to enter into

21. a somatic dialogue with my own body. Through this dialogue, I was able to

22. make new and useful discoveries about my movement, enriching my dance

23. practice in a way that would not have been possible had the question never

24. been asked. Thus, the students' word became part of my own discourse,

25. informing and shaping the way I perceive my own practice and allowing me

26. to reflect more deeply on my position as a teacher of dance technique.

27.

28.

29.

30.

31.

32.

33.

34.

35.

36.

37.

38.

39.

40.

41.

42.

43.

44.

45.

46.

47.

48.

49.

50.

51.

52.

Not only has dialogue helped me to understand how students may perceive the movement ideas being explored in our classes, but by engaging with the students' word, I have become more aware of their interests. This collaborative relationship between teacher and students enables the content and direction of the class to be shaped by all of us. With transparency around the pedagogical approaches being utilized and by clarifying the beliefs and values that underpin these approaches, together, teacher and students may develop a discourse around the learning that occurs in the dance technique class that empowers both parties to continue exploring possibilities in relation to the acts of teaching and learning, if, indeed they are distinct from each other.

\section{RefeRenceS}

Aceto, M. (2012), 'Developing the dance artist in technique class: The alteration task', Journal of Dance Education, 12:1, pp. 14-20.

Alexander, R. (2008), Essays on Pedagogy, London: Routledge.

- - (2017), Towards Dialogic Teaching: Rethinking Classroom Talk, York: Dialogos.

Andersson, N. and Thorgersen, C. (2015), 'From a dualistic toward a holistic view of dance knowledge: A phenomenological analysis of syllabuses in upper secondary schools in Sweden', Journal of Dance Education, 15:1, pp. 1-11.

Anttila, E. (2007a), 'Mind the body: Unearthing the affiliation between the conscious body and the reflective mind', in L. Rouhiainen (ed.), Ways of Knowing in Dance and Art, Helsinki: Theatre Academy, pp. 79-99. 
- - (2007b), 'Searching for dialogue in dance education: A teacher's story', Dance Research Journal, 39:2, Winter, pp. 43-57.

1.

Bakhtin, M. M. (1981), The Dialogic Imagination: Four Essays (ed. M. Holquist), Austin: University of Texas Press.

Bannon, F. (2010), 'Dance: The possibilities of a discipline', Research in Dance Education, 11:1, pp. 49-59.

Batson, G. (2009), 'Somatic studies and dance', International Association for Dance Medicine and Science, https://c.ymcdn.com/sites/www.iadms.org/ resource/resmgr/imported/info/somatic_studies.pdf. Accessed 21 August 2017.

Bradbury, H. (ed.) (2015), The SAGE Handbook of Action Research, 3rd ed., Los Angeles: SAGE.

Brodie, J. and Lobel, E. (2004), 'Integrating fundamental principles underlying somatic practices into the dance technique class', Journal of Dance Education, $4: 3$, pp. 80-87.

Dryburgh, J. and Jackson, L. (2016), 'Building a practice of learning together: Expanding the functions of feedback with the use of the flipchart in contemporary dance technique', Research in Dance Education, 17:2, pp. 130-44.

Dyer, B. (2009), 'Merging traditional technique vocabularies with democratic teaching perspectives in dance education: A consideration of aesthetic values and their sociopolitical contexts', Journal of Aesthetic Education, 43:4, pp. 108-23.

- - (2010), 'The perils, privileges and pleasures of seeking right from wrong: Reflecting upon student perspectives of social processes, value systems, agency and the becoming of identity in the dance technique classroom', Research in Dance Education, 11:2, pp. 109-29.

- - (2014), 'Exploring social and moral learning frameworks through collaborative enquiry', Journal of Dance Education, 14:2, pp. 45-51.

Eddy, M. (2009), 'A brief history of somatic practices and dance: Historical development of the field of somatic education and its relationship to dance', Journal of Dance and Somatic Practices, 1:1, pp. 5-27.

Enghauser, R. (2007), 'Developing listening bodies in the dance technique class', Journal of Physical Education, Recreation \& Dance, 78:6, pp. 33-38.

Fortin, S. (1998), 'Somatics: A tool for empowering modern dance teachers', in S. Shapiro (ed.), Dance, Power and Difference: Critical and Feminist Perspectives On Dance Education, Champaign, IL: Human Kinetics, pp. 49-73.

Fortin, S., Long, W. and Lord, M. (2002), 'Three voices: Researching how somatic education informs contemporary dance technique classes', Research in Dance Education, 3:2, pp. 155-80.

Fortin, S., Vieira, A. and Tremblay, M. (2009), 'The experience of discourses in dance and somatics', Journal of Dance and Somatic Practices, 1:1, pp. 47-64.

Freire, P. (1996), Pedagogy of the Oppressed, rev. ed., London: Penguin.

Gelb, M. (2004), Body Learning: An Introduction to the Alexander Technique, London: Aurum Press Limited.

Green, J. (1998),'Engendering bodies: somatic stories in dance education', The Annual Meeting of the American Educational Research Association, San Diego, CA, 13-17 April.

- - . (1999), 'Somatic authority and the myth of the ideal body in dance education', Dance Research Journal, 31:2, pp. 80-100.

- - (2001), 'Socially constructed bodies in American dance classrooms', Research in Dance Education, 2:2, pp. 155-73. 
1. $\quad$ - - (2002), 'Somatic knowledge: The body as content and methodology in dance education', Journal of Dance Education, 2:4, pp. 114-18.

Hanna, T. (1988), Somatics: Reawakening the Mind's Control of Movement, Flexibility and Health, Reading, MA: Addison-Wesley.

Hanstein, P. (1990), 'Educating for the future: A post modern paradigm for dance education', Journal of Physical Education, Recreation and Dance, 61:5, pp. 56-58.

Holquist, M. (2002), Bakhtin and his World, London: Routledge.

Jefferson, A. (1989), 'Bodymatters: Self and others in Bakhtin, Sartre and Barthes', in K. Hirschop and D. Shepherd (eds), Bakhtin and Cultural Theory, Manchester: Manchester University Press, pp. 152-77.

Johnson, D. (1992), Body: Recovering our Sensual Wisdom, Berkeley, CA: North Atlantic Books and Somatic Resources.

Ladyshewsky, R. K. (2013), 'The role of peers in feedback processes', in D. Boud and E. Molloy (eds), Feedback in Higher and Professional Education: Understanding it and Doing it Well, London: Routledge, pp. 174-88.

Matusov, E. and Duyke, K. von (2010), 'Bakhtin's notion of the internally persuasive discourse in education: Internal to what? (A case discussion of issues of foul language in teacher education)', in K. Junefelt and P. Nordin (eds), Proceedings from the Second International Interdisciplinary Conference on Perspectives and Limits of Dialogism in Mikhail Bakhtin, Stockholm University, Stockholm, 3-5 June 2009.

McAteer, M. (2013), Action Research in Education, London: SAGE.

McNiff, J. (2013), Action Research: Principles and Practice, 3rd ed., Oxon: Routledge.

McArthur, J. and Huxham, M. (2013), 'Feedback unbound: From master to usher', in S. Merry, M. Price, D. Carless and M. Taras (eds), Reconceptualising Feedback in Higher Education: Developing Dialogue with Students, Abingdon: Routledge, pp. 92-102.

Råman, T. (2009), 'Collaborative learning in the dance technique class', Research in Dance Education, 10:1, pp. 75-87.

Rimmer, R. (2016), 'Questions as"springboards": A dialogic approach to fostering critical enquiry and reflection in dance', Learning and Teaching in Action, 12:1, pp. 83-100.

- - (2017), 'Negotiating the rules of engagement: Exploring perceptions of dance technique learning through Bourdieu's concept of "doxa"', Research in Dance Education, 18:3, pp. 231-36.

Robinson, A. (2011), 'In theory Bakhtin: Dialogism, polyphony and heteroglossia', https://ceasefiremagazine.co.uk/in-theory-bakhtin-1/. Accessed 27 May 2017.

Ryan, M. (2012), 'Conceptualising and teaching discursive and performative reflection in higher education', Studies in Continuing Education, 34:2, pp. 207-23.

Sartre, J. P. (1957), Being and Nothingness: An Essay on Phenomenological Ontology (trans. H. Barnes), York: Methuen.

Shapiro, S. (ed.) (1998), 'Toward transformative teachers: Critical and feminist perspectives in dance education', in Dance, Power and Difference: Critical and Feminist Perspectives on Dance Education, Champaign, IL: Human Kinetics, pp. 7-21.

Skidmore, D. and Murakami, K. (eds) (2016) Dialogic Pedagogy: The Importance of Dialogue in Teaching and Learning, Bristol: Multilingual Matters. 
Stanton, E. (2011), 'Doing, re-doing and undoing: Practice, repetition and critical evaluation as mechanisms for learning in a dance technique class "laboratory"', Theatre, Dance and Performance Training, 2:1, pp. 86-98.

Stevens, J. (2006), Re-Thinking Dance Technique in Higher Education, Report from the Higher Education Academy Palatine Seminar, Leicester, De Montfort University, 29 November.

Stinson, S. (1993), 'Journey towards a feminist pedagogy for dance', Women $\mathcal{E}$ Performance: A Journal of Feminist Theory, 6:1, pp. 131-46.

Weber, R. (2009), 'Integrating semi-structured somatic practices and contemporary dance training', Journal of Dance and Somatic Practices, 1:2, pp. 237-54.

\section{SuggeSted citation}

Rimmer-Piekarczyk, R. (2018), 'Self-somatic authority: Exploring the cultivation of somatic intelligence through a dialogic approach to self-reflection in dance technique learning', Journal of Dance \& Somatic Practices, 10:1, pp. 79-94, doi: 10.1386/jdsp.10.1.79_1

\section{contributor details}

Rachel Piekarczyk (nee Rimmer) holds a BA (community arts and dance) and an MA (Contemporary Arts) from Manchester Metropolitan University (MMU) where she is currently undertaking a practice-led Ph.D. in dance pedagogy. To develop this research, in September 2015 she was awarded a Scholarship of Teaching and Learning by the Centre of Excellence for Learning and Teaching at MMU. She is the subject lead for the BA (Hons) in dance programme at MMU in Cheshire and a fellow of the Higher Education Academy. She is also a performer with Reckless Sleepers and has been touring internationally with the company since 2012 in their projects 'A String Section' and 'Negative Space'.

Contact: Department of Contemporary Arts, Manchester Metropolitan University in Cheshire, Crewe Green Road, CW1 5DU, UK.

E-mail: r.s.piekarczyk@mmu.ac.uk

Rachel Rimmer-Piekarczyk has asserted her right under the Copyright, Designs and Patents Act, 1988, to be identified as the author of this work in the format that was submitted to Intellect Ltd. 